\title{
During Repetitive Forebrain Ischemia, Post-ischemic Hypothermia Protects Neurons from Damage
}

\author{
Ashfaq Shuaib, Sadiq Ijaz, Jay Kalra and William Code
}

\begin{abstract}
In rodents damage from repetitive transient cerebral ischemia is more severe than that seen with a single ischemic insult of similar duration. Mild hypothermia has been shown to be very effective in protecting the brain during single ischemic insults. We tested the protective effects of hypothermia in repetitive ischemic insults. We used the gerbil model of repetitive ischemia (three minutes ischemia repeated at one hourly intervals three times) and histological evaluation was done using the silver staining technique. Our study reveals that a decrease in body and scalp temperature by 1-2 degrees Celsius can significantly reduce neuronal damage in the cerebral cortex, CAl region of the hippocampus and substantia nigra reticulata during repetitive ischemia. As the hypothermia was induced after the initial insult, we believe this offers an opportunity for intervention in the clinical settings.

RÉSUMÉ: Pendant l'ischémie répétitive du cerveau antérieur l'hypothermie post-ischémique préserve l'intégrité des neurones. Chez les rongeurs, les dommages dus à l'ischémie cérébrale transitoire répétitive sont plus sévères que ceux que l'on observe lors d'un seul épisode ischémique de même durée. Il a été démontré qu'une légère hypothermie est très efficace pour protéger le cerveau pendant un épisode ischémique unique. Nous avons évalué l'effet protecteur de l'hypothermie lors d'épisodes ischémiques répétés. Nous avons utilisé la souris gerbille comme modèle d'ischémie répétitive (trois périodes d'ischémie de trois minutes à une heure d'intervalle) et nous avons procédé à une évaluation histologique par la technique de coloration à l'argent. Notre étude révèle qu'une baisse de la température du corps et du cuir chevelu de 1 ou 2 degrés Celsius peut diminuer significativement le dommage neuronal dans le cortex cérébral, la région CAl de l'hippocampe et la zone réticulée de la substance noire pendant l'ischémie répétitive. Comme l'hypothermie a été induite après l'agression initiale, nous croyons que cette observation suggère la possibilité d'une telle intervention dans un contexte clinique.
\end{abstract}

Can.J. Neurol. Sci. 1992; 19:428-432

Cardiac disease and stroke together account for over $50 \%$ of the mortality in North America. In cardiac disease, neuronal damage is commonly a result of serious ventricular arrhythmias or asystole (global cerebral ischemia). In small animals the extent and severity of the neuronal damage in global ischemia is dependent on the duration of the insult and several other important variables including brain temperature, blood glucose levels and the type of animal model. With 5-10 minutes of reversible global ischemia in rats and gerbils, there is predictable and fairly consistent damage in the cortex (layers 3-5), hippocampus (CA1 and CA4) and striatum. Damage in the CA1 region of the hippocampus is delayed, beginning up to two to three days after reperfusion. This delay (known as delayed neuronal damage) offers hope of intervention before the damage becomes apparent.

Repetitive global cerebral ischemia can result from cardiac arrhythmia, severe hypotension and anesthesia accidents. There is considerable evidence that neuronal damage resulting from repetitive ischemia is cumulative and exceeds the damage from a similar duration single ischemia insult. ${ }^{1.2}$ In addition, neuronal damage is seen in regions of the brain not commonly affected during a single ischemic insult. ${ }^{3}$ Understanding of mechanisms whereby repetitive ischemia results in more severe damage is important as this could lead to the development of treatment strategies.

In experimental ischemia (focal and global), mild to moderate hypothermia has been successfully used to offer cerebral protection. ${ }^{4.5}$ This effect is seen when temperature is decreased during or even up to one-half hour after the ischemic insult. Hypothermia has been shown to be protective during ischemia in cell culture systems ${ }^{6}$ and several species of research animals. ${ }^{4.5}$ In this study we tested the hypothesis that hypothermia, when used between episodes of repetitive ischemia, protects cerebral neurons from the effects of ischemia.

\section{Materials ANd MethodS}

Male Mongolian gerbils weighing 50-70 grams were used for all experiments. Animals were acclimatized to the vivarium for

From the Departments of Medicine (Division of Neurology) (A.S.), Pathology (J.K.) and Anesthesia, Cerebrovasular Research Laboratory (S.I.), and Saskatchewan Stroke Research Centre (W.C.), College of Medicine, University of Saskatchewan, Saskatoon

Received December 9, 1991. Accepted in final form April 8, 1992.

Reprint requests to: Dr. A. Shuaib, Dept. of Medicine, Royal University Hospital, Saskatoon, Saskatchewan, Canada S7N 0X0 
one week with free access to water and food. Repetitive ischemia was performed by the methods of Araki et al.' Briefly, animals were anesthetized with halothane $3 \%$ and a mixture of nitrous oxide (70\%) and oxygen (30\%). This was followed by insertion of rectal and scalp electrodes for temperature measurement. The scalp temperatures were used as a non-invasive means of monitoring brain temperatures. ${ }^{7}$ The majority of animals in both groups had continous electroencephalographic monitoring. A midcervical incision was then made and both carotid arteries carefully exposed. Aneurysm clips were then applied to both carotid arteries. After visual inspection to verify arterial occlusion, the halothane anesthesia was stopped but the nitrous oxide mixture remained unchanged. After three minutes of arterial occlusion, the clips were removed, the neck wound sutured and the animal allowed to recover. The procedure of arterial occlusion was repeated at one hour and two hours, each time for three minutes. In six animals, the whole body temperature was decreased to 34-35 degrees Celsius, in between the arterial occlusions, using methods described by Chopp et al. ${ }^{8}$ Briefly, hypothermia was instituted by spraying alcohol on the gerbil's body while a fan circulated room air around the animal. When the rectal temperature reached 34.5 degrees, the fan was shut off until such time that the temperature was higher again. In three animals the temperature was normally maintained but the body was sprayed with alcohol to rule out any direct protective effects of the alcohol. After completion of ischemia, the animals were returned to the vivarium and were sacrificed and perfused seven days later. At the time of sacrifice, the animals were anesthetized with an overdose of sodium pentothal and a thoracotomy was performed. The left heart was cannulated and the animal perfused, initially with $150 \mathrm{ml}$ of normal saline, followed by $150 \mathrm{ml}$ of $0.1 \mathrm{M}$ sodium phosphate buffer (with $10 \%$ formalin) at $7.4 \mathrm{pH}$. After one hour, the brains were removed and placed in 30\% sucrose for 3-7 days for cryoprotection. The brains were then cut in 40 micron sections and stained with a modification of the silver impregnation method of Gallya's. 9.10 Briefly, the sections were washed with water, pretreated with alkaline ammonium nitrate, impregnated with $0.32 \%$ silver nitrate in alkaline ammonium nitrate, treated with ethanolic sodium carbonate/ammonium nitrate solution and finally developed in Nauta reducer. Representative sections were cut through the striatum, hippocampus, thalamus, substantia nigra reticulata and the medial geniculate nucleus. Tissue planes were made according to the rat atlas of Paxinos and Watson" and the gerbil atlas of Loskota et al. ${ }^{12}$

Neuronal damage was assessed with light microscopy. Damage was scored with previously described methods, ${ }^{3}$ as a modification of the Pulsinelli score ${ }^{13}$ and Kato's score. ${ }^{14}$ No damage $=$ 0 , less than $25 \%$ damage $=1,25-75 \%$ damage $=2,75-100 \%$ damage $=3$, cerebral infarction $=4$. Damage was assessed independently in the two hemispheres and all histological evaluation was done in a blinded manner.

Statistical analysis was done using a statistical software package, EP15.0I (USD Incorporated, Stone Mountain, GA). For most comparisons of histological data we used the KruskalWallis one-way ANOVA data generated by the software.

\section{RESULTS}

There were six animals with repetitive ischemia and no hypothermia. Six animals had repetitive ischemia along with hypothermia in between the ischemic episodes. Finally three animals were sprayed with alcohol but their temperatures were maintained close to 37 degrees. All animals survived the ischemia insult and were sacrificed seven days later.

\section{Behavioural Effects}

Recovery from ischemia was associated with a humped posture that was maintained for 15 minutes after the first insult. This increased to approximately 25 minutes after the second insult and 40 minutes after the third insult. This posturing is very typical of animals that have received forebrain ischemia. There appeared to be no clear behavioural differences between the animals exposed to ischemia alone or where ischemia was combined with hypothermia.

\section{Physiological Effect}

It was easy to maintain hypothermia of 34-36 degrees Celsius between the ischemia episodes (Table 1). There are very small differences between the brain and scalp temperature. ${ }^{7}$ We therefore used scalp temperatures instead of brain temperatures because this was a non-invasive method of monitoring the head temperatures, especially during the intervals between the ischemic insults. EEG would show electrical silence within seconds of the occlusion of the carotid arteries. Recovery of EEG activity did not appear to differ in the two groups.

\section{Morphological Effects}

Neuronal damage in the group with no hypothermia was very severe. Ischemic damage was seen in the hippocampus, striatum, thalamus, substantia nigra reticulata and the medial geniculate nucleus. Two animals showed infarctions in the striatum and the substantia nigra. Severity of damage is shown in Figure 1.

In the animals that were exposed to hypothermia between the episodes of ischemia, neuronal damage was significantly milder. In the striatum most animals had mild to moderate damage and the damage was restricted to the dorsal and lateral portions. Hippocampal damage was restricted to the neuropil in most animals. The damage was most obvious in the CA-4 region. In the

This table shows the temperature measurements in the hypothermic and normothermic animals. We were able to rapidly decrease the body and scalp temperatures between the ischemic insults without difficulty and maintain it at the low level until the next insult.

\begin{tabular}{|c|c|c|c|c|c|c|c|}
\hline Group & 1 & 2 & 3 & 4 & 5 & 6 & 7 \\
\hline a & $\begin{array}{r}37.7 \\
{[.10]}\end{array}$ & $\begin{array}{r}37.4 \\
{[.01]}\end{array}$ & $\begin{array}{r}35.6 \\
{[.20]}\end{array}$ & $\begin{array}{l}37.4 \\
{[.01]}\end{array}$ & $\begin{array}{r}35.6 \\
{[.20]}\end{array}$ & $\begin{array}{l}37.5 \\
{[.01]}\end{array}$ & $\begin{array}{r}35.5 \\
1.18]\end{array}$ \\
\hline b & $\begin{array}{r}37.5 \\
{[.2]}\end{array}$ & $\begin{array}{r}37.5 \\
{[0.2]}\end{array}$ & $\begin{array}{r}37.6 \\
{[.11]}\end{array}$ & $\begin{array}{r}37.5 \\
{[.02]}\end{array}$ & $\begin{array}{r}37.6 \\
{[.08]}\end{array}$ & $\begin{array}{r}37.5 \\
{[.10]}\end{array}$ & $\begin{array}{r}37.6 \\
{[.10]}\end{array}$ \\
\hline c & $\begin{array}{c}36.6 \\
{[.14]}\end{array}$ & $\begin{array}{r}36.5 \\
{[.01]}\end{array}$ & $\begin{array}{r}34.6 \\
{[.14]}\end{array}$ & $\begin{array}{r}36.4 \\
{[.04]}\end{array}$ & $\begin{array}{l}34.5 \\
{[.12]}\end{array}$ & $\begin{array}{r}36.4 \\
{[.02]}\end{array}$ & $\begin{array}{l}34.6 \\
{[.10]}\end{array}$ \\
\hline d & $\begin{array}{c}36.8 \\
{[0.6]}\end{array}$ & $\begin{array}{l}36.6 \\
{[.10]}\end{array}$ & $\begin{array}{l}36.7 \\
{[.06]}\end{array}$ & $\begin{array}{l}36.5 \\
{[.04]}\end{array}$ & $\begin{array}{r}36.8 \\
{[.02]}\end{array}$ & $\begin{array}{r}36.5 \\
{[.10]}\end{array}$ & $\begin{array}{l}36.6 \\
{[.10]}\end{array}$ \\
\hline
\end{tabular}

Group a: Scalp temperature of hypothermic animals. Group b: Scalp temperature of normothermic animals. Group c: Core temperature of hypothermic animals. Group d: Core temperature of normothermic animals.

1: Pre-ischemic, 2: First ischemia, 3: First reperfusion, 4: Second ischemia, 5: Second reperfusion, 6: Third ischemia and 7: Third reperfusion. Values are mean with standard deviation listed within [ ]. 


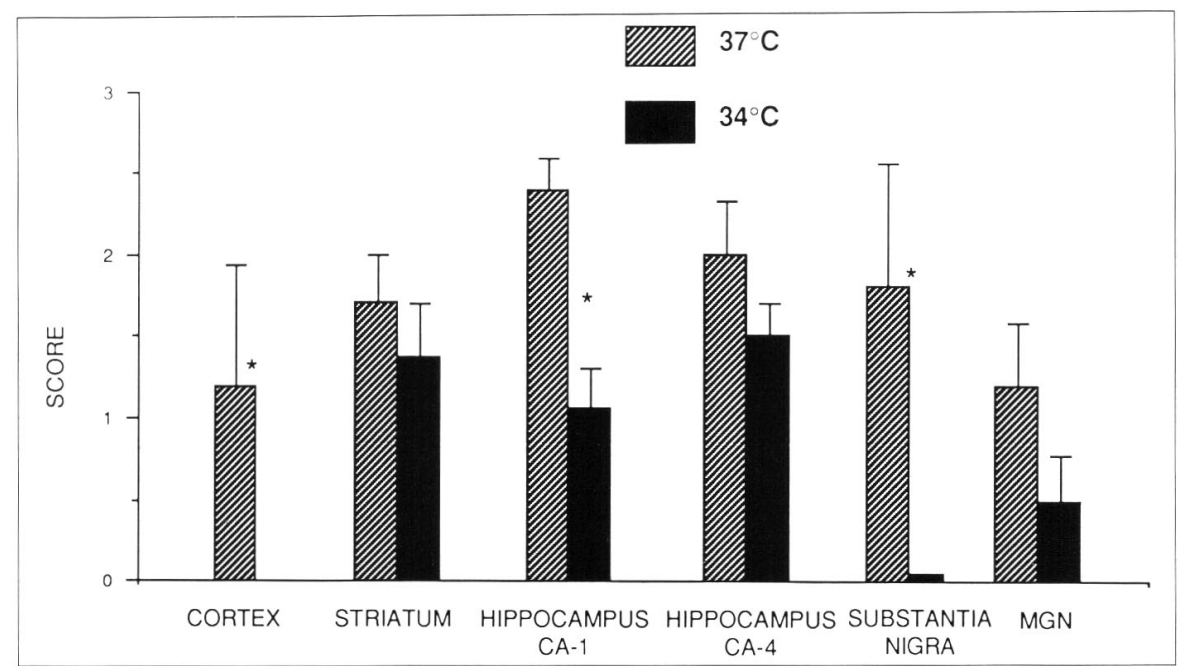

Figure I - This figure shows the damage scores in the hypothermic and normothermic control animals with three times three minutes ischemia. The ischemic insults were produced one hour apart. Damage scores are compared in the cerebral corter, striatum CAI and CA4 regions of the hippocampus, substantia nigra reticulata and the medial geniculate nucleus (MGN). There was significantly less damage in the cerebral cortex, hippocampus (CAl) and the substantia nigra reticulata in the hypothermic animals.

CA-1, damage was restricted to the stratum oriens and was mostly seen in rostral regions of the brain. The extent of damage in the control (non-ischemic), hypothermic and normothermic animals with repetitive ischemia is shown in Figure 2. There was very little cell body involvement. This damage was not evident on Nissl staining. Thalamic, substantia nigra reticulata and medial geniculate nucleus damage was seen in some brains and was mostly restricted to the neuropil. Infarcts were not seen in any animal. When compared to normothermic control animals, neuronal damage was significantly less severe in the cortex, $\mathrm{CA}-\mathrm{I}$ region of the hippocampus and the substantia nigra reticulata (Figure 1).

In the animals where alcohol was sprayed but temperature was maintained as normal, the extent of brain damage was no different than the control gerbils (no alcohol, no hypothermia).

\section{Discussion}

Repetitive cerebral ischemia was initially described by Tomida et al. in 1987. The severity of neuronal damage after repetitive ischemia is more pronounced and extensive than a single insult of a similar duration. ${ }^{2.15}$ Clinically, repetitive global ischemia may be seen in patients with recurrent transient ischemic attacks, cardiac arrhythmias, severe hypotension and anesthesia accidents. The mechanisms of how repetitive ischemia produces more damage than a similar duration single ischemic insult is poorly understood but is under investigation. Our experiment clearly shows that reduction of body and brain temperature by as little as three degrees between the ischemic insults results in significant protection of the brain from the effects of ischemia. This protection was present in all animals. Because brain temperature was reduced immediately after the insult it is possible that this protection can also be put to clinical use in conditions that result in repetitive cerebral ischemia such as anesthesia-related cerebral ischemic insults.
It has long been known that hypothermia is neuroprotective. Earlier studies in larger animals had clearly shown that reduction of brain temperature by 7-10 degrees Celsius (severe hypothermia) was beneficial to the brain. ${ }^{16}$ Because such degrees of hypothermia were very uncomfortable, it could not be widely used in clinical practice. Recently, it has been shown that even milder hypothermia of 33-35 degrees Celsius can offer cerebral protection and have the potential for clinical application. ${ }^{4.8 .17-23}$ Mild hypothermia has been shown to be neuroprotective when used during and even immediately after ischemia. Protection has been seen in gerbils, ${ }^{18,24}$ rats, ${ }^{17.20 .25 .26}$ dogs ${ }^{19,20.27}$ and monkeys. ${ }^{16}$ The exact mechanism of hypothermic protection is as yet unestablished but is most likely multi-factorial. A slow down in the metabolic activity, reduced release of excitatory aminoacids, decreased production of lactate, prevention of cerebral edema and inhibition of breakdown of adenine nucleotide are some of the proposed mechanisms whereby hypothermia may protect neurons from the effects of ischemia. The protective effects of hypothermia may not be limited to neurons only. We have recently demonstrated that astrocytes in primary culture survive the effects of ischemia better if the temperature is reduced by 2 3 degrees Celsius during the insult. ${ }^{6}$

It has recently been shown that during repetitive cerebral ischemia there is an increased build-up of extra-cellular glutamate and this remains elevated for a prolonged time period. ${ }^{28}$ This is in contrast to a single ischemic insult, where the glutamate concentrations are usually down to the baseline within an hour of the insult. Cerebral ischemia under hypothermic conditions has been shown to attenuate the extracellular build-up of dopamine and glutamate. ${ }^{29} \mathrm{~A}$ decrease in build-up of such compounds (which have both been shown to affect neuronal cell death during ischemia) may be one possible mechanism whereby hypothermia offers protection during repetitive ischemia. An increase in brain temperature has been shown to increase neuronal damage after cerebral ischemia. ${ }^{30}$ Hyperthermia during 

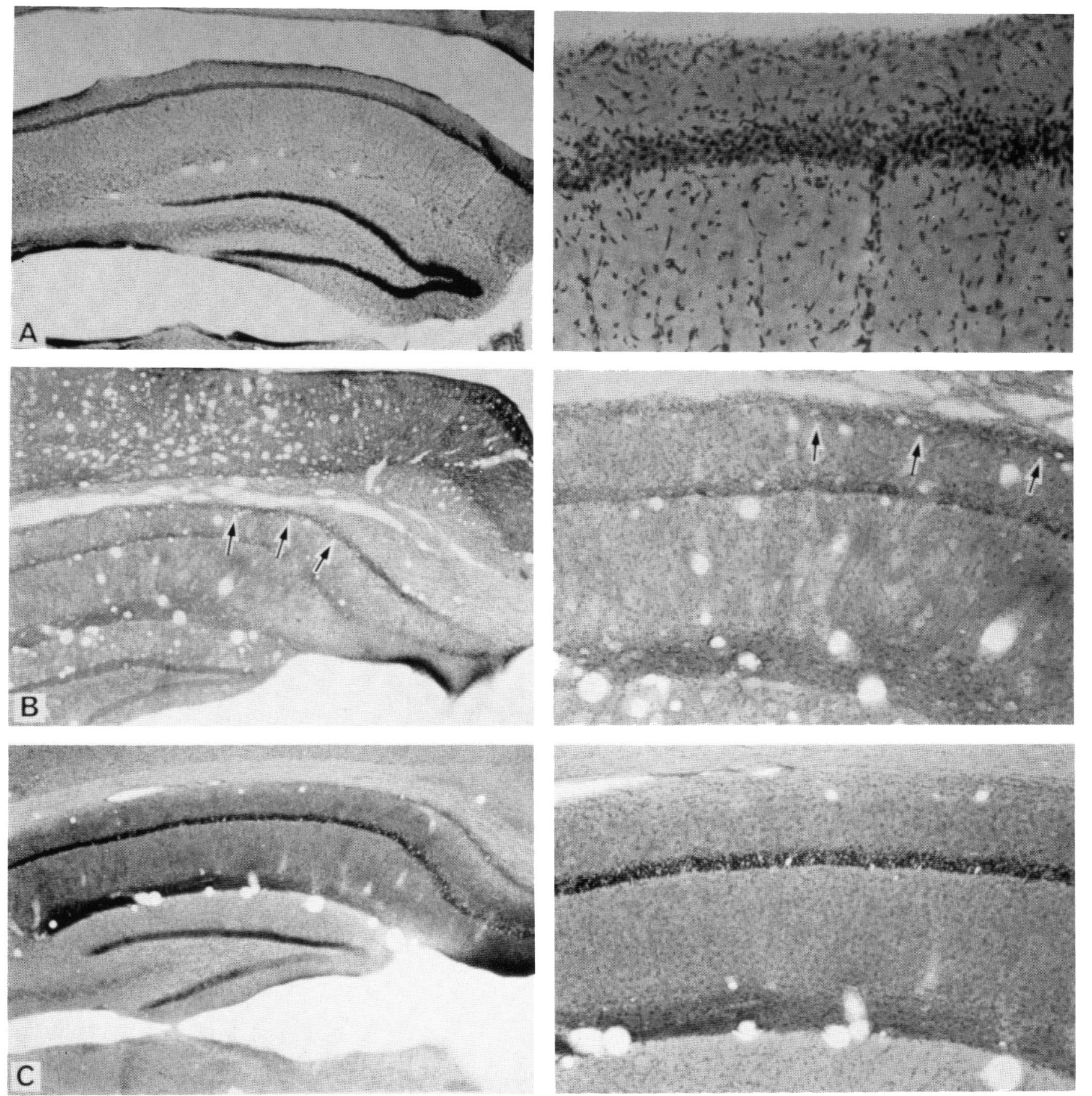

Figure 2 - This figure compares the extent of damage in the hippocampus in normal no ischemia controls (A), hypothermic (B), and normothermic (C) ischemic animals with thee minutes times three episodes of ischemia. As is evident from the photomicrographs, there is considerable protection in the CAI region of the hippocampus in the hypothermic animals $(B)$. The neuropil damage in stratum oriens (arrow's) was mostly restricted to the rostral CAI regions in the hypothermic animals. In the animals with no hypothermia, the full extent of CAl was damaged (C).

repetitive ischemia does not appear to increase neuronal damage in gerbils. ${ }^{14}$

Our experiment also demonstrates the usefulness of silver impregnation staining in the study of repetitive cerebral ischemia. The neuropil damage evident in the CA-1 region of the hippocampus of the hypothermic animals was not seen with
Nissl staining. Similarly, most damage in the medial geniculate nucleus and the substantia nigra reticulata was also restricted to the neuropil and may have been missed with conventional staining techniques. Damaged neurons, dendrites and axons appear dark against a brown background, which makes interpretation easy and decreases the potential of missing mild damage. ${ }^{31}$ 


\section{ACKNOWLEDGEMENT}

This research was supported by a grant from the Saskatchewan Health Research Board and the Saskatchewan Heart and Stroke Foundation. Doris Kanigan and Nadia Afridi helped in preparation of the manuscript.

\section{REFERENCES}

1. Araki T, Kato $H$, Kogure $K$. Neuronal damage and calcium accumulation following repeated brief cerebral ischemia in the gerbil. Brain Res 1990; 528: 114-122.

2. Nakano S, Kato H, Kogure K. Neuronal damage in the rat hippocampus in a new model of repeated reversible transient cerebral ischemia. Brain Res 1989; 490: 178-180.

3. Shuaib A, Ijaz S, Kalra J, Code W. Substantia nigra reticulata damage is delayed in repetitive cerebral ischemia. Brain Res 1992; 574: 120-124.

4. Young RSK, Olenginski TP, Yagel SK, Towfighi J. The effect of graded hypothermia on the hypoxic-ischemic brain damage: a neuropathologic study in the neonatal rat. Stroke 1983; 14: 929934.

5. Herschkowitz FSN, Stoller EBM, Cross TA, Aue WP, Seelig J. Cerebral metabolic studies in situ by 3 l p-nuclear magnetic resonance after hypothermia circulatory arrest. Pediatric Res 1986; 20: 867-871.

6. Shuaib A, Hertz L, Code WE. Hypothermia protects astrocytes in cell culture during hypoxia. Ann Neurol 1991; 30: 319.

7. Busto R, Dietrich WD, Globus MYT, Valdes I, Scheinberg P, et al. Small differences in intraischemic brain temperature critically determine the extent of ischemic neuronal injury. J Cereb Blood Flow Metab 1987; 7: 729-738.

8. Chopp M, Chen H, Dereski MO, Garcia JH. Mild hypothermic intervention after graded ischemic stress in rats. Stroke 1991; 22: 37-43.

9. Gallyas F, Wolff JR, Bottcher H, Zaborszby L. A reliable method to localize axonal damage after axotomy. Stain Tech 1980; 55: 291 . 297.

10. Gallyas F, Wolff JR, Bottcher H, Zaborszky L. A reliable and sensitive method to localize terminal degeneration and lysosomes in the central nervous system. Stain Tech 1980; 55: 299-306.

11. Paxinos G, Watson C. The Rat Brain in Stereotaxic Coordinates. Sydney, New York: Academic Press, 1982.

12. Loskota WJ, Lomax P, Verity MA. A Stereotaxic Atlas of the Mongolian Gerbil Brain. Ann Arbor: Ann Arbor Publishers Inc., 1974.

13. Pulsinelli WA, Brierly JB, Plum F. Temporal profile of neuronal damage in a model of transient forebrain ischemia. Ann Neurol 1982; 11: 491-498.

14. Kato H, Araki T, Kogure K. Postischemic spontaneous hyperthermia is not a major aggravating factor for neuronal damage following repeated brief cerebral ischemia in the gerbil. Neurosci Lett 1991; 126: $21-24$.

15. Kitagawa $K$, Matsumoto $M$, Tagaya $M$, et al. Ischemic tolerance phenomenon found in the brain. Brain Res 1990; 528: 21-24.
16. Kopf GS, Mirvis DM, Myers RE. Central nervous tolerance to cardiac arrest during profound hypothermia. J Surg Res 1975; 18 : 29-34.

17. Busto R, Globus MYT, Dietrich WD, Martinez E, Valdes l, et al. Effects of mild hypothermia on ischemia-induced release of neurotransmitters and free fatty acids in rat brain. Stroke 1989;20: 904-910.

18. Buchan A, Pulsinelli WA. Hypothermia but not NMDA antagonist MK-801, attenuates neuronal damage in gerbils subjected to transient global ischemia. J Neurosci 1990; 10: 311-316.

19. Marshall SB, Swan H. Temporary circulatory occlusion to the brain of the hypothermic dog. Arch Surg 1956; 72: 98-106.

20. Leonov Y, Sterz F, Safar P, et al. Mild cerebral hypothermia during and after cardiac arrest improves neurologic outcome in dogs. J Cereb Blood Flow Metab 1990; 10: 57-70.

21. Busto RBS, Dietrich D, Globus M Y-T, Valdes I, Scheinberg P, et al. Small differences in intraischemic temperatures critically determine the extent of ischemic neuronal injury. J Cereb Blood Flow Metab 1987; 7: 729-738.

22. Hagedal M, Welsh FA, Keykhah MM, Perez E, Harp JR. Protective effects of combinations of hypothermia and barbiturates in cerebral hypoxia in the rat. Anesthesiology 1978; 49: 165-169.

23. Bailes JE, Leavitt ML, Teeple E Jr, et al. Ultraprofound hypothermia with complete blood substitution in a canine model. J Neurosurg 1991; 74: 781-788.

24. Clifton GL, Taft WC, Blair RE, Choi SC, DeLorenzo RJ. Conditions for pharmacological evaluation in the gerbil model of forebrain ischemia. Stroke 1989; 20: 1545-1552.

25. Vacanti FX, Ames III A. Mild hypothermia and Mg protects against irreversible damage during CNS ischemia. Stroke 1984; 15: 695698.

26. Busto RBS, Dietrich D, Globus M Y-T, Ginsberg M. Postischemic moderate hypothermia inhibits CAI hippocampal ischemic neuronal injury. Neurosci Lett 1989; 101: 299-304.

27. Natale JE, D'Alecy LG. Protection from cerebral ischemia by brain cooling without reduced lactate accumulation in dogs. Stroke 1989; 20: 770-777.

28. Lim B, Globus M Y-T, Dietrich D, et al. Different morphological and neurochemical sequelae of global ischemia: comparison of single and multiple paradigms. J Cereb Blood Flow Metab 1991; 11 (Suppl 2): S854.

29. Busto RBS, Globus M Y-T, Dietrich D, Martinez E, Valdes I, Ginsberg M. Effects of mild hypothermia on ischemia induced release of neurotransmitters and free fatty acids in the rat brain. Stroke 1989; 20: 904-910.

30. Dietrich D, Busto R, Valdes I, Loor Y. Effects of normothermic versus mild hyperthermic forebrain ischemia in rats. Stroke 1990; 21: 1318-1325.

31. Crain BJ, Westerkam WD, Harrison AH, Nadler JV. Selective neuronal death after transient forebrain ischemia in the Mongolian gerbil: a silver impregnation study. Neuroscience 1988; 27: 387402 . 